
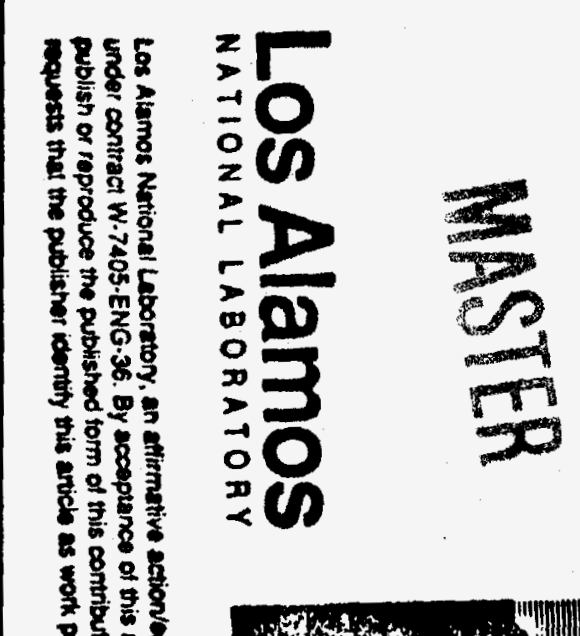

웅

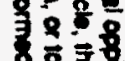

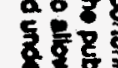

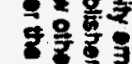

응

88

$2.8 \%$

可题

कing

8 害寉

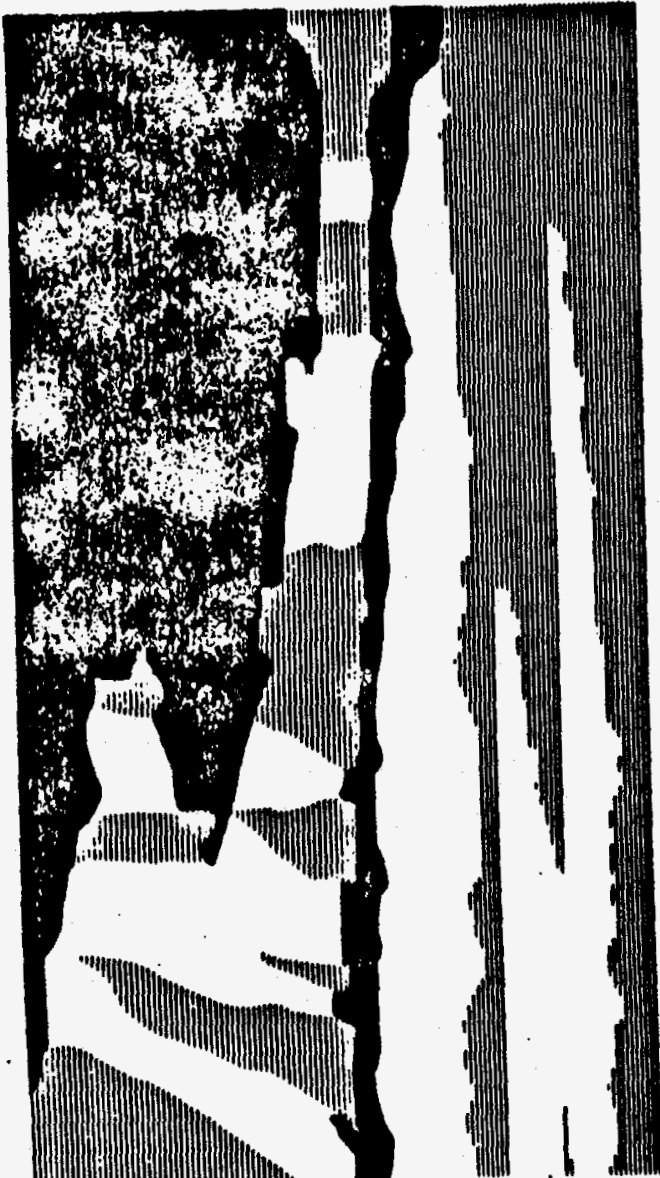

\section{DISCLAIMER}

This report was prepared as an account of work sponsored by an agency of the United States Government. Neither the United States Government nor any agency thereof, nor any of their employees, makes any warranty, express or implied, or assumes any legal liability or responsibility for the accuracy, completeness, or usefulness of any information, apparatus, product, or process disclosed, or represents that its use would not infringe privately owned rights. Reference herein to any specific commercial product, process, or service by trade name, trademark, manufacturer, or otherwise does not necessarily constitute or imply its endorsement, recommendation, or favoring by the United States Government or any agency thereof. The views and opinions of authors expressed herein do not necessarily state or reflect those of the United States Government or any agency thereof.

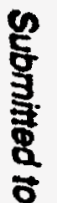

홍

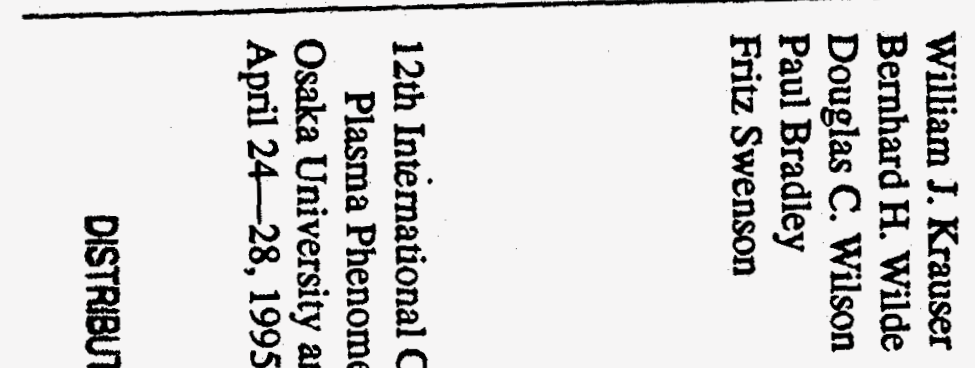

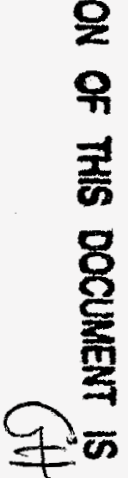

影

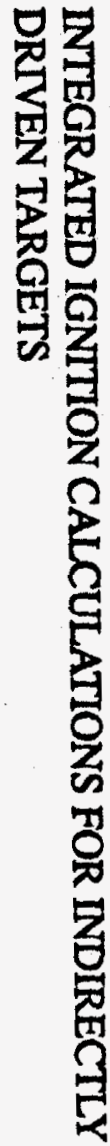

$\sum_{1}^{0}$
0
0
0
$\frac{1}{0}$
$\frac{1}{1}$
$\frac{1}{1}$ 


\section{DISCLAIMER}

Portions of this document may be illegible in electronic image products. Images are produced from the best available original document. 


\title{
Integrated Ignition Calculations for Indirectly Driven Targets*
}

\author{
William J. Krauser, Bernhard H. Wilde, Douglas C. Wilson, Paul \\ Bradley, and Fritz Swenson
}

\author{
Los Alamos National Laboratory \\ Los Alamos, New Mexico 87545 USA
}

\begin{abstract}
We present two-dimensional LASNEX calculations of the hohlraum and ignition capsules proposed for the National Ignition Facility (NIF). Our current hohiraum design is a $2.76 \mathrm{~mm}$ radius, $9.49 \mathrm{~mm}$ long gold cylinder with $1.39 \mathrm{~mm}$ radius laser entrance holes (LEH) which are covered by $1 \mu \mathrm{m}$ thick polyamide foils. Laser beams with less that 1.4 MJ total energy and less than $400 \mathrm{TW}$ peak power irradiate the cylinder wall from two separate cones entering each LEH. The hoblraum interior is flled with hydrogen-helium gas ( $50-50$ atomic) at a density of $0.83 \mathrm{mg} / \mathrm{cm}^{3}$ to suppress the inward expansion of the wall. The capsule uses either a $160 \mathrm{\mu m}$ plastic ablator doped with bromine (the baseline design), or a $155 \mu \mathrm{m}$ beryllium ablator doped with copper (the beryllium design). The ablator surrounds an $80 \mu \mathrm{m}$ thick deuterium-tritium (DT) ice layer with an inner radius of $0.87 \mathrm{~mm}$. We will show the results of integrated, two-dimensional calculations of the hohlraum and the capsule. Plasma conditions within the hohlraum will be described. Peak radiation temperatures in the hohlraum are about $300 \mathrm{eV}$. These calculations proceed through the implosion, ignition, and burn of the DT capsule. Current peak calculated yields are $12 \mathrm{MJ}$ for the baseline design and $6.9 \mathrm{MJ}$ for the capsule with the beryllium ablator, although higher yields should be achievable with improved "tuning" of the laser power levels.
\end{abstract}

*This work supported under USDOE contract W-7405-ENG-36.

\section{Introduction}

As currently proposed, the NIF laser is a 192 beam frequency tripled Nd:glass system providing a peak power of $500 \mathrm{TW}$ and a total energy of $1.8 \mathrm{MJ}$. The baseline NIF ignition target design (1) is indirect drive. In this technique laser light is utilized to heat the interior walls of a high- $Z$ cylindrical enclosure, or hohlraum. The hohlraum serves to isotropize and thermalize the initially highly localized and non-Planckian $\mathrm{X}$-rays created when the laser light is absorbed. A spherical capsule 
in the hohlraum is irradiated nearly uniformly from almost all directions by the $x$ rays filling the hohlraum. A highly symmetric ablation-driven implosion of the capsule results.

The baseline capsule is cryogenic with a DT ice shell surrounding a central DT gas region. The ice, in turn, is surrounded by an ablator. The hohlraum radiation temperature peaks at $\sim 300 \mathrm{eV}$ and has a carefully shaped pre-pulse which keeps the fuel and the ablator on a low adiabat during the long, high-convergence-ratio $(\sim 20-35)$ implosion. For the baseline capsule and hohlraum, the peak hohlraum temperature cannot be pushed much higher than $300 \mathrm{eV}$ because the hohlraum will fill too rapidly with plasma blown off from the hohlraum wall, which prevents subsequent laser beam propagation within the hohlraum. Also, laser-plasma instabilities become more severe at the higher intensities needed to drive a hohlraum to higher temperature. At a lower peak temperature, a capsule implosion with a higher convergence ratio (i.e., a thinner ice shell at larger initial radius) would be required to achieve the same fuel density and yield. In order not to quench the ignition, there must be little mixing of the ignition hotspot with the cooler main fuel. The higher the convergence ratio, however, the larger the growth of inevitable initial perturbations on, for example, the ice-ablator interface. If this growth is too large, catastrophic hotspot mixing will occur and the capsule will fail to ignite. The baseline hohlraum and capsule design occupies a prudent compromise location in this parameter space.

\section{Modeling requirements}

In designing or assessing the performance of hohlraums and ignition targets for the NIF, we need to model a wide variety of physical phenomena that occurs during the course of the implosion. Examples include the refraction, reflection, and absorption of laser light passing through the spatially and temporally varying laser entrance holes; the filling of the hohlraum with plasma; laser-plasma interactions including instability seeding and growth; the spot motion of the laser absorption region; the time dependent emission of $\mathrm{x}$-rays from the laser-heated plasma, their absorption on and re-radiation from the hohlraum walls, and final absorption in the capsule ablator; the spatial and temporal variation of the capsule ablation; the capsule implosion and short-wavelength hydrodynamic instability growth and mixing within the capsule; and thermonuclear burn. No single code exists today which is capable of modeling simultaneously all of these phenomena, some of which require a three-dimensional treatment.

\section{The integrated modeling approach}

The best we can do currently is to combine the hohlraum and capsule calcula- 
tions into a single two-dimensional (2-D) radiation-hydrodynamics calculation using the LASNEX code (2) with the laser light as the energy input. These "integrated calculations," each of which requires $\sim 100$ hours of time on a Cray-YMP, generally use the best available numerical packages for laser ray tracing (3), radiation transport, non-local thermodynamic equilibrium (non-LTE) atomic physics (4) in the hohlraum wall, hydrodynamics (mostly Lagrangian, but with a semiEulerian rezoning treatment $(5,6)$ for material in or near the LEH's), and fusion burn. This comprehensive but computationally intensive technique was developed over the last three years and includes many of the effects listed above; nevertheless the calculations are incomplete. For example, the calculation of colliding low density plasmas is performed with Lagrangian hydrodynamics and does not model plasma interpenetration. Laser plasma instabilities such as Brillouin and Raman scattering are not explicitly modeled. However, the integrated calculations only use approximately $1.4 \mathrm{MJ}$ of laser energy, leaving $0.4 \mathrm{MJ}$ of the NIF laser design energy to account for these and other losses. And capsule mixing and yield degradation due to short scale length hydrodynamic instability growth must be modeled separately (7). The techniques and physics packages used in integrated modeling of the NIF have been used in modeling relevant NOVA experimental data $(8,9)$. The excellent agreement between those calculations and the data increases our confidence that the modeling techniques and physics packages are adequate.

\section{Hohlraum and ignition target description}

There are many possible hohlraum and ignition capsule designs. We have focussed our work on one hohlraum design and on two different capsule designs (see Fig. 1). Our colleagues at Lawrence Livermore Laboratory designed one of the capsules, the baseline capsule, and the basic hohlraum, a $9.49 \mathrm{~mm}$ long by 2.76 $\mathrm{mm}$ radius gold cylinder, $40 \mu \mathrm{m}$ thick, with $1.39 \mathrm{~mm}$ radius LEH's on either end. We added a $10 \mu \mathrm{m}$ thick plastic liner around the lip of the LEH to help keep it open. The capsule uses either a $160 \mu \mathrm{m}$ thick polystyrene (plastic) ablator doped with bromine, or a $155 \mu \mathrm{m}$ thick beryllium ablator doped with copper. The ablatorsurrounds an $80 \mu \mathrm{m}$ thick DT ice layer with an inner radius of $0.87 \mathrm{~mm}$. The ablator dopant serves to reduce $\mathrm{x}$-ray preheat in the ablator and eliminates an unstable density step at the ablator/DT interface.

Our first integrated calculations used a $2.5 \mu \mathrm{m}$ thick plastic lining on the gold hohlraum walls with the expectation that it would slow the expansion of the gold wall into the (nearly evacuated) hohlraum center. However we found that the plastic stagnated on axis, creating a modest pressure pulse which caused the capsule to implode too early on the pole and prevented ignition. Our solution was to remove the plastic liner and fill the hohlraum with gas at a density $\sim 1 \mathrm{mg} / \mathrm{cm}^{3}$. Since the capsule must be maintained at about $18^{\circ} \mathrm{K}$, the gas could be only hydrogen or helium, or a mixture of the two. Our most recent design uses $0.833 \mathrm{mg} / \mathrm{cm}^{3}$ of a 




Figure 1. NIF capsules and hohlraum. The gas-filled, gold-walled hohlraum is driven by 192 laser beams (1.8 MJ, $500 \mathrm{TW}$ ) arrayed in inner and outer cones.

50-50 (atomic) mixture. The mixture of gases minimizes stimulated Brillouin scattering (SBS). To contain the gas prior to firing the lasers, we covered each LEH with a $1 \mu \mathrm{m}$ thick polyimide foil. With these changes stagnation pressures were reduced to the point where they no longer degraded the capsule implosion. Fig. 2 shows that throughout the laser pulse the gas fill successfully holds back the gold walls of the hohlraum and maintains hohlraum plasma densities comfortably less than the critical electron density.

As shown in Fig. 1, the laser light coming in each LEH is in two cones, an "inner" cone which illuminates the hohlraum wall near the waist of the capsule, and an "outer" cone which illuminates an area of the wall closer to the LEH. This arrangement was chosen so that the time-dependent asymmetry of the radiation incident on the capsule can be minimized by dynamically varying the relative power in the cones.

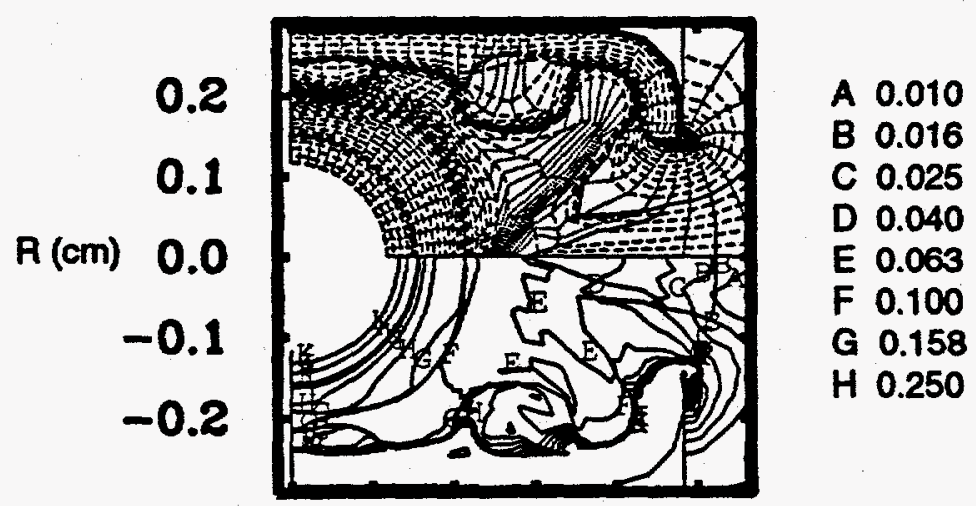

Figure 2. Mesh (upper) and contours (lower) of fraction of critical electron density at time of peak laser power (14.5 ns), from an integrated calculation. 


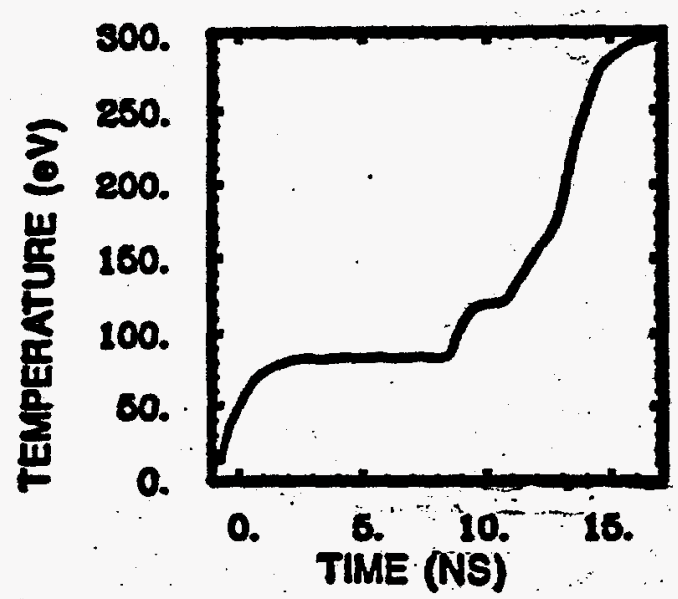

Figure 3. Ideal radiation temperature drive for the plastic capsule.

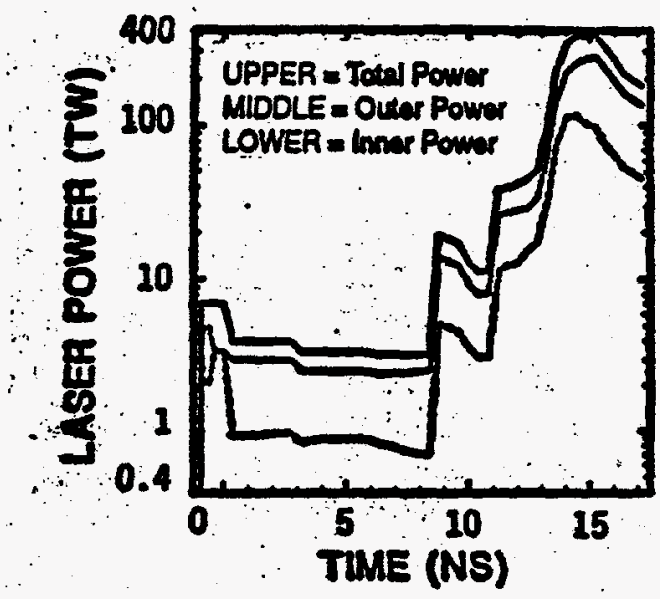

Figure 4. Laser power levels needed to approximate temperature drive and give good capsule symmetry.

\section{Achieving ignition in integrated calculations}

A 1-D clean calculation of the implosion and burn of the plastic capsule with an ideal radiation temperature drive shown in Fig. 3 gives a yield of $14.7 \mathrm{MJ}$. This drive, which peaks at $300 \mathrm{eV}$, creates four shocks in the capsule, with the final shock bringing the ablator up to peak pressure with sufficiently low entropy in the fuel. Since the NIF target will not be in a 1-D environment, integrated modeling calculations must be employed throughout the hohlraum and target design process, as well as in efforts to verify that the overall design has a reasonable chance of achieving ignition, the primary NIF goal. In a 2-D integrated calculation of a particular capsule and hohlraum, the only input variables are the laser pointings and the laser power levels. In iterative calculations, the total laser power time history is adjusted until the hohlraum radiation temperature history reasonably approximates the ideal profile. In general the capsule will fail to ignite at this stage because asymmetries in the drive cause too much distortion in the final configuration of the capsule.

It is customary to quantify the radiation drive asymmetry by expanding the radiative flux incident on the capsule in terms of spherical harmonics, which reduce to Legendre polynomials on the surface of a sphere having cylindrical symmetry. The independent variable in the expansion is the angle $\theta$, which is $0^{\circ}$ at the capsule pole and $90^{\circ}$ at the capsule equator. Left-right symmetry in the hohlraum ensures that the odd moments $P_{1}, P_{3}$, etc., in the expansion vanish. The $P_{0}$ moment is the average flux incident on the capsule and is roughly proportional to the fourth power of the hohlraum radiation temperature. $\mathrm{P}_{2}$ is a measure of the pole-to-equator asymmetry. A positive $P_{2}$, for example, means that the capsule is "pole hot," perhaps due to the outer cone of laser beams having too much power relative to the inner cone thus causing the hohlraum wall near the LEH to appear hotter than the wall near the capsule equator. If this coefficient is mostly positive throughout the 
implosion, the capsule generally will be "pancaked" at ignition time. Ideally, all but the $\mathrm{P}_{\mathbf{0}}$ moment are zero, so the design problem is to minimize all of the higher moments.

$P_{2}$ and $P_{4}$ are minimized in the next series of calculations. The relative power levels in the inner and outer laser cones are adjusted dynamically (i.e., the beams are "phased") to minimize $P_{2}$ at all times. With two cones (per side), this time dependent control is possible only for the $\mathrm{P}_{2}$ coefficient. Blowoff of the hohlraum wall causes the position of the laser absorption region on the wall to move radially inward during the illumination. As viewed from the location of the capsule, this "spot motion" makes the hot region on the wall due to the outer cone appear to move steadily toward the LEH. With a judicious pointing of the cones (i.e., the initial spacing between the inner and outer rings of illumination on the hohlraum wall) it is possible to achieve a time averaged value near zero for $\mathbf{P}_{4}$. Direct control, even in a time averaged sense, of the higher moments is not possible. Fig. 4 shows typical laser power levels needed to approximate the desired hohlraum temperature and achieve adequate capsule symmetry in the integrated calculation of the plastic ablator capsule. Fig. 5 shows typical $\mathrm{P}_{2}$ and $\mathrm{P}_{4}$ moments.

Minimizing the capsule drive asymmetry in this manner leads to acceptable implosion symmetry followed by ignition and burn. The plastic design yields 12.2 $\mathrm{MJ}$ and the beryllium capsule produces $6.9 \mathrm{MJ}$ in integrated calculations. The beryllium design achieves $17.4 \mathrm{MJ}$ in 1-D simulations, and with more tuning of the integrated calculations to decrease the drive asymmetry we believe its yield could be raised substantially.

\section{Robustness studies}

Two capsules ignite and burn in integrated calculations, but how believable are these results? To better quantify the probability of successful ignition, we have

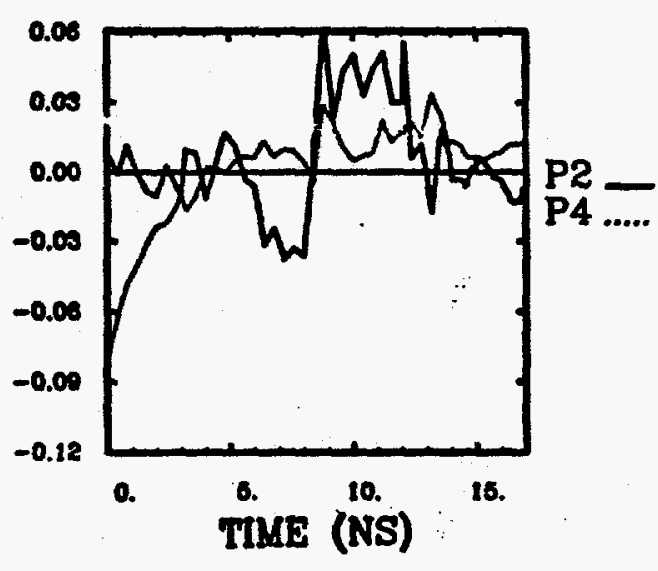

Figure 5. Typical $P_{2} / P_{0}$ and $P_{4} / P_{0}$ moments of the incident radiation flux on the capsule.

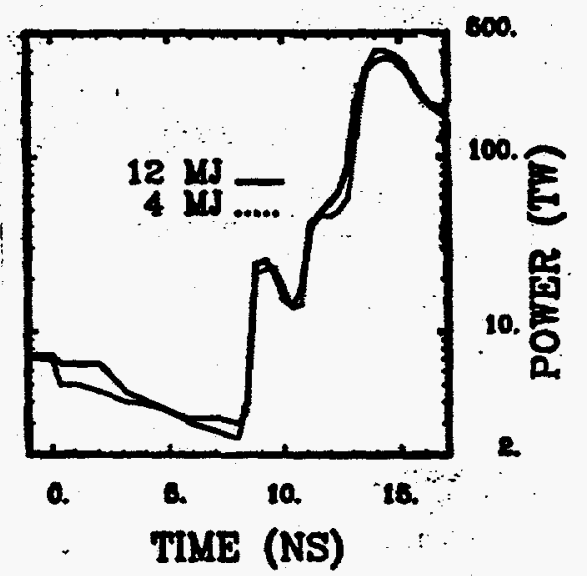

Figure 6. The nearly optimum power profile gives $12 \mathrm{MJ}$. Non-optimum profile gives $4 \mathrm{MJ}$ in the integrated calculations. 
performed numerous robustness studies of the NIF design. We have examined sensitivities to the length, shape, and gas fill density of the hohlraum, and we are assessing whether a very thin plastic lining on the hohlraum wall might offer certain advantages.

For the capsule, we have examined the effects of asymmetric radiation drive and non-ideal radiation temperature drive profile. Fig. 6 shows a laser power profile modestly different from the optimized profile (the laser specifications easily allow one to control the power to this level of accuracy). This non-optimum profile yielded only $4 \mathrm{MJ}$ in the integrated calculation for the plastic capsule.

For the laser we are examining sensitivities to pointing and beam phasing. One pleasantly surprising, totally unanticipated observation was that no beam phasing is required for certain optimum pointings. For less than optimum pointings (e.g., moving the outer cone $100 \mu \mathrm{m}$ toward the LEH), beam phasing is required to get adequate burn.

Finally, we are examining sensitivities to some of the modeling approximations in LASNEX: we are investigating different hydro techniques, different electron conductivity approximations, different equations of state and opacities, and LTE vs. non-LTE atomic physics treatments. Our non-LTE atomic physics package attempts to model the time dependence of the level populations in the laser irradiated gold plasma. This enhancement causes less radiation emission from the laser deposition regions and more gold plasma motion.

\section{Conclusions}

In summary, using our best integrated calculations we confirm Livermore calculations of ignition with a plastic capsule, and we have added an alternate capsule design with a beryllium ablator. Although robustness calculations show the designs are sensitive, they add to our confidence that NIF can achieve ignition. Many additional calculations remain to be performed.

\section{ACKNOWLEDGMENTS}

We wish to thank our colleagues at Lawrence Livermore Laboratory, particularly Steve Haan and Steve Pollaine, who have collaborated with us and shared their capsule and hohlraum designs. This work is supported by the USDOE under contracts W-7405-ENG-36 and W-7405-ENG-48. 


\section{REFERENCES}

1. Haan, S. W. et al., "Design and Modeling of Ignition Targets for the National Ignition Facility," to be published in Physics of Plasmas 2 (1995).

2. Zimmerman, G. B., and Kruer, W. L., Comments Plasma Physics of Controlled Thermonuclear Fusion 2, 51 (1975).

3. Friedman, A. Lawrence Livermore Laboratory Laser Program Annual Report No. UCRL-50021-83, 1983, pp. 3-51.

4. Post, D. E. et al., Atomic Data and Nuclear Data Tables 20, 397 (1977); Zimmerman, G. B., and More, R. M., Joumal of Quantitative Spectroscopy and Radiative Transfer 23, 517 (1980).

5. Hoffman, N. M. et al., "Nonlinear multimode instability modeling for national ignition facility capsules," presented at 12th International Conference on Laser Interaction and Related Plasma Phenomena, Osaka, Japan, April 24-28, 1995.

6. Brackbill, J., and Saltzman, J., Journal of Computational Physics 46, 342 (1982).

7. Scannapieco, A., Los Alamos National Laboratory Report No. LA-UR-82-2897 (1982).

8. Lindman, E. L. et al., "Modeling of drive-symmetry experiments in gas-filled hohlraums at NOVA," presented at 12th International Conference on Laser Interaction and Related Plasma Phenomena, Osaka, Japan, April 24-28, 1995.

9. Suter, L. J. et al., "Modeling and Interpretation of Nova's Symmetry Scaling Data Base," Physical Review Letters 73, 2328-2331 (1994). 